\title{
On preparing for the great gift of community that climate-disasters can give us
}

\section{By Rupert Read.}

"That we carry on like this is the catastrophe." - Walter Benjamin.

"The recovery of [a sense of] purpose and closeness without crisis or pressure is the great contemporary task of being human. Or perhaps the dawning era of economic and environmental disasters will solve the conundrum for us more harshly." - Rebecca Solnit.

The greenhouse gases we've already unleashed commit us to grave new natural (sic.) disasters.

There is a widespread (if rarely spoken about) assumption, among those who dare (as few do) to understand - to see with open eyes - the character of the future which climate chaos is likely to yield, the world of escalating 'natural' (sic) disasters which we are bequeathing to our children and to their children. That assumption is that civility will give way and a Hobbesian war of all against all will be unleashed. (Think The Road, or at best The Hunger Games.)

Thankfully, the assumption is highly questionable.

In this article, I set out why, by appealing to too-little-known results that have been found in the interdisciplinary academic field of 'Disaster Studies' (section 1). I then outline that we nevertheless need to find a deliberate and pro-active way of answering the question (of whether civility will be diminished or perhaps instead in truth even significantly improved, by climate-disasters) in the right way (section 2); we most certainly cannot just leave it to 'history' to sort things out, without our own agency. I then emphasise a dimension of the agency that we have as philosophers/intellectuals/communicators: a practicable way of getting us to think/feel/care for others, locally and globally, and across time. Namely, by starting with the importance to us of our own children (section 3). I round things out with a few conclusions - mainly through bringing together the insights of section 2 and 3 - and some thoughts of further directions for research (section 4).

Before any of that, however, I need briefly to address the worry that my title may already have raised, for some readers. Perhaps putting them off. How dare one speak of disaster as potentially the bringer of a gift (Section 0)?: 
[0] We know now that dangerous anthropogenic climate change is not merely a matter of a glacially-slow steady increase in world temperature. Such global over-heat (aka 'global warming') is real, and may well be the worst single element of anthropogenic climate change. But the more immediately noticeable effect, for most people, for a long time to come, is likely to be climate chaos. And the weather chaos that is the most immediate manifestation thereof. We are talking an increased incidence of ultra-powerful storms, floods, droughts; and more striking or surprising phenomena, such as the possibility of the Gulf Stream temporarily or permanently 'switching off', or of a permanent EI Nino.

In other words, for a long time to come, the most noticeable and perhaps the most damaging impact of the heating that we have unleashed will be events that will manifest as disasters. We are going to see 'biblical' (sic) floods, hurricanes of unprecedented scale, and much much more.

These will be disasters. I am not quarelling with that verdict, that nomenclature. We can foresee right now the deaths of millions, perhaps of tens or even hundreds of millions, from these disasters. That is a terrible thing. It's a terrible thing even to have to foresee, to contemplate it; let alone for it to be experienced, suffered, as it almost certainly will be.

In the current piece, I explain why these disasters, though terrible, will nevertheless not be unmitigated. In fact, they will provide us with an opportunity for something wonderful, and necessary.

When disaster occurs, one can simply be defeated by it. Or indeed one can use it to make things even worse for others (as in the 'Shock Doctrine', named by Naomi Klein). Or: one can quite literally make the best of it. I think that we should make absolutely no apology for choosing, if ever possible, the third of these three options.

The argument that I make in the following section is that making the best of disaster is in simple fact (though the fact is remarkable, and gives great hope) what comes naturally to human beings. In particular, I shall suggest that human beings today particularly in those parts of the world (more and more of it) where terrible strain has been put on any and all traditional embedding of life in communities that can be relied upon are even yearning for such an opportunity. I don't, of course, mean that people are yearning for disaster to strike. I mean that very very many of us are living lives of quiet desperation, more or less inchoately awaiting something that can enable such communities to be recreated.

Disaster, when it comes, is of course unwelcome, terrible. It would be a twisted theodicy which would try to make of such disasters nothing but a good thing. It is not the best of all possible times, if one has to endure disaster (still less, obviously, if that disaster wipes one and/or one's loved ones out). But yet, disaster can yield an astonishing, direly needed gift. As I shall now describe.

[1] Let me begin the body of this essay by speaking personally. In doing so, I will try to break further through a wall of 'stealth denial' that I think we virtually all tend to build around us, today, even those of us who are well aware of the likelihood (on a business-as- 
usual pathway) of a potentially-irrecoverable civilisational collapse within the next generation or three.

For well over a decade now, I have been afraid of the nightmare that (I thought) would unfold, if true disaster, likely as a result of climate-chaos, for example through food shortage, comes to a place like England, where I live. I have engaged in some fragments of serious through seemingly hopeless 'prepping': that is the term used by those (of us) who are actively preparing for the contingency of such future-disasters through trying to equip ourselves and our loved ones with some means to survive them. I have not infrequently been in a state of some anxiety about such possible futures. I believe, incidentally, that one of the main reasons why disaster-movies and (especially) apocalypse-movies (and it is notable that the latter have been increasing in number in recent years) are popular is: that they provide a 'safe' environment for the mass public to explore their (our) conscious or unconscious fears about the feasible coming of such disasters. ${ }^{1}$

It is by coming to understand something of the field of Disaster Studies that I have finally reached a state of some peace and indeed optimism, in relation to all this.

And how did I become open to the ideas of this field, in the first place? 'Disaster Studies', as I understand it, yields conclusions that fly wildly in the face of 'conventional wisdom' about disasters and chaos, and that meet and answer many of my (and perhaps your) anxieties about how quickly things could collapse and how dire they could get, in our fragile, long-supply-lined, overly-complex 'globalised' world. How does one even get to the point where one can contemplate an alternative to frantic 'prepping' and to anxiety, or indeed to the more usual response, of denial?

For me, what is in retrospect the key moment came early in 2002. I couldn't process it at the time - it pretty-much 'bounced off' the frame through which I saw the world. But it came back to me and motivated me, when, much more recently, I happened across Rebecca Solnit's work.

It consisted in this: I was conversing, in January 2002, in New York, with an American friend, a New Yorker, about his having been present in the city during the September 11th 2001 attacks. I had recently wandered around the 'Ground Zero' exWorld-Trade-Centre site, and been concerned and downhearted by the often-violent graffiti and messages left there expressing a desire for vengeance on those who had carried out the attack (and sometimes on anyone who looked like them or shared ancestry with them). I said to my friend, whose politics were close to mine: "It must have been just awful, being in New York in those days after the attacks. I mean: with all the death, the terrible smell, the deadly pollution, the chaos, and worst of all the ferocious yells for vengeance." His reply completely flummoxed me. He said: "Actually, it was the one time in my life that I ever felt part of a community. It sounds strange to say it, but it was actually a happy time. People spoke to each other. Strangers helped each other - and this is New York,

\footnotetext{
${ }^{1}$ I will return to this point in section 2, below: by examining a couple of such movies, that I have already mentioned.
} 
remember! Distinctions fell away." And, after a pause, he said, again, "It was truly the one time in my life when I have ever felt like I was really: part of a community."

Years later, when I came into contact with Rebecca Solnit's A paradise built in hell: The extraordinary communities that arise in disaster (2009), that memory suddenly came powerfully back to me. And instantly I saw how maybe this very surprising, very encouraging thing could be true. Perhaps, contrary to what, in our 'liberal' individualist culture we assume, people don't become degraded and reduced to nasty brutish selfish types, when they are put under extreme pressure: perhaps that isn't our actual 'state of nature'. Perhaps, more often, the reverse.

I am no scholar of Disaster Studies. So I will use here as my guides to the field two main sources: Solnit's recent book, and Charles Fritz's classic of the field, tragically unpublished for 35 years after it was written, "Disasters and mental health: Therapeutic principles drawn from Disaster Studies". ${ }^{2}$

What does their work show?

Drawing in detail on many examples, from the 1906 San Francisco earthquake to $11 / 9 / 2001$, from the devastating explosion in Halifax Nova Scotia to Hiroshima, from the Blitz to Hurricane Katrina, Fritz and Solnit suggest to us that disaster tends to enable new communities to be born. Instantly, and often lastingly.

They relate how, against our expectations of chaos and panic, people in the immediate aftermath of a disaster are often remarkably calm. How they tend rapidly to develop mutual networks of support, based on need rather than on prior distinctions whether of wealth of ethnicity or what-have-you. How looting, though often assumed to be inevitable, is actually rare (and how, in any case, some of what is described as looting would be much more reasonably described as the harnessing of supplies; for remember, we are talking here, often, about people suddenly desperately short of life's necessities). ${ }^{3}$ How, remarkably, it is at least as common for people to 'converge' on the scene of a disaster, in order to help, as it is for people to flee. ${ }^{4}$

And how all of this - against a backdrop, remember, of fear, loss, injury, death, often affecting most of the survivors directly — happens relatively spontaneously, rapidly, and even joyfully. How this festival of altruism is not even experienced primarily under that star: people don't find themselves, as they help and care for others, in the aftermath of disaster, to be engaging in self-sacrificial behaviour. It comes naturally to them, rather, and is experienced by them as something they want to do, even something it actually helps them to engage in the doing of. (Solnit, p.197)

Here is a contemporary account of the phenomenon from a survivor of the great San Francisco earthquake: "Most of us since [the earthquake] have run the whole gamut of human emotions from glad to sad and back again, but underneath it all a new note is

\footnotetext{
${ }^{2}$ http://udspace.udel.edu/handle/19716/1325

${ }_{3}$ Sometimes, sadly, the authorities and/or the media will describe a favoured group as gathering supplies, when the same activity engaged in by a non-favoured group is called looting. Solnit, in Chapter V of her book, documents this as having happened in New Orleans, vis-à-vis whites and blacks, respectively.

4 This phenomenon of 'convergence' was particularly striking in the case of September 2001. See

"The need to help", p.195ff. of Solnit's book.
} 
struck, a quiet bubbling joy is felt. It is that note that makes all our loss worth the while. It is the note of a millenial good fellowship... In all the grand exodus [from the most devastated areas of San Francisco]...everybody was your friend and you in turn everybody's friend. The individual, the isolated self was dead. The social self was regnant. Never even when the four walls of one's own room in a new city shall close around us again shall we sense the old lonesomeness shutting us off from our neighbours... And that is the sweetness and the gladness of the earthquake and the fire. Not of bravery, nor of strength, nor of a new city, but of a new inclusiveness. // The joy is in the other fellow." 5

This, I believe, is a key to the meaning of what happens in disasters. A possibility of joy, because of community that was previously absent. (Note how we in the UK often remark, and are vaguely surprised by, the nostalgia that so many have for the Second World War. This is the explanation of it, I believe. The Blitz wasn't in the main experienced (only) as an awful, anxiety-making mortal threat. It was experienced (more) as the occasion for a new, genuine community.)

We are living, nowadays, in ways that involve us in a virtually permanent and (to coin a phrase) disastrous absence of community. Disasters enable this to be overcome.

It is important to note that, for this overcoming to take place, typically, there has to be a disaster. Not merely an accident or something bad. Fritz emphasises this point especially. He writes (p.21) that disasters need to be big enough to not leave "an undisturbed, intact social system". Only if that system IS disrupted sufficiently can the new forms of community emerge. The ground has to change, so to speak. Only then can a new figure emerge...

"Disaster provides an unstructured social situation that enables persons and groups to perceive the possibility of introducing desired innovations into the social system", Fritz goes on to argue (p.56). Moreover, in disaster (though not in lesser upheavals), "Many preexisting invidious social distinctions and constraints to social mobility are removed; there is a general democratization of the social structure" (p.66).

This latter feature in particular can have really helpful 'knock-on' effects. Consider the way that, to almost everyone's surprise, the British electorate in 1945 ejected the 'war hero' Prime Minister Churchill from office, and replaced him with the great reforming Labour Government that began that year, and created the NHS and so much more. This amazing event I think starts to make more sense, under the aspect that I have sought to make prominent here.

Or consider a fascinating lesser-known example that Solnit sets out at some length in Chapter III: that of the 1985 Mexico City earthquake, that is widely credited by those who know with creating the conditions of possibility for the ejection from power (after 3 generations in constant control) of the basically-corrupt PRI Party in that country.

We hear a lot today about Post-Traumatic Stress. Fritz et al seek to teach us about something less well-know, but just as important. It is sometimes now called "post-traumatic growth." 6

${ }^{5}$ Quoted in Solnit, p.32. Emphasis mine.

${ }^{6}$ Cf. p.220 of Solnit. 
Solnit makes the most of this by means of offering some deft reminders of etymology, reminders worth quoting at length:

"The word emergency comes from emerge, to rise out of, the opposite of emerge, which comes from mergere, to be within or under a liquid, immersed, submerged. An emergency is a separation from the familiar, a sudden emergence into a new atmosphere, one that demands we ourselves rise to the occasion. Catastrophe comes from the Greek kata, or down, and streiphen, or turning over. It means an upset of what is expected and was originally used to mean a plot twist. To emerge into the unexpected is not always terrible, though these words have evolved to imply ill fortune. The word disaster comes from the Latin compound of dis- or away, without, and astro, star or planet: literally, without a star.

"In some of the disasters of the twentieth century - the big northeastern blackouts in 1965 and 2003, the 1989 Loma Prieta earthquake in the San Francisco Bay Area, 2005's Hurricane Katrina on the Gulf Coast [and, in a different way, the blackout in the Blitz] — the loss of electrical power meant that the light pollution blotting out the night sky vanished. In these disaster-struck cities, people suddenly found themselves under the canopy of stars still visible in small and remote places. On the warm night of August 15 2003, the Milky Way could be seen in New York City, a heavenly realm long lost to view until the blackout that hit the NorthEast late that afternoon. You can think of the current social order as something akin to this artificial light: another kind of power that fails in disaster. In its place appears a reversion to improvised, collaborative, cooperative and local society. However beautiful the stars of a suddenly visible night sky, few nowadays could find their way by them. But the constellations of solidarity, altruism and improvisation are within most of us and reappear at these times... This is the paradise entered through hell." (p.10)

Solent's rather beautiful thoughts here rhyme with those of Thomas Homer-Dixon, who, in The upside of down: Catastrophe, creativity, and the renewal of civilisation, goes one further, coining (on p.22) a new word, catagenesis. Meaning the birth of something original from out of something disastrous. Or, as he more bluntly characterises it (on p.268): "the creative renewal of our technologies, institutions, and societies in the aftermath of breakdown."

Perhaps you have figured out where I am going with all this. My hypothesis is: that the rising tide of disasters that climate chaos will bring could be the (re-)making of us. These two wonderful works, of Fritz's and Solnit's, make evident that, when actually tested in the crucible of back-to-back disasters, it is at least as likely that humanity will rise to the challenge, and be transformed for the better in the process, as it is that we will shun the victims. What Fritz et al suggest, on my extrapolation of it, is that we will likely find ourselves manifesting a truer humanity than we currently think ourselves to have, in this climate-stressed future that we are now entering into. We do not have to be gripped by the doomy thought that we are about to prove Hobbes and his many contemporary followers right. Instead, we can be optimistic that we are about to prove them wrong, as they have in fact, if largely unnoticedly, been proven wrong so many times before. 
Thus the post-normal, climate-stressed world offers us a tremendous gift amidst the carnage, a gift we may well, remarkably, even welcome and literally make the best of.

[2] l've argued that an escalating series of climate disasters will yet carry with them as an unexpected boon an opportunity for the development of community. A great chance for us to show our quality.

But: how much and how well we actually realise this gift depends on our preparing the way for it, rather than probabilifying the other main realistic possibility - unrestrained destructive authoritarian elite panic in the face of disaster.

For just is something else that Fritz and Solnit alike make clear: that often things do go wrong in the wake of disaster, and most often as a result of (a largely delusive, but nevertheless consequential) elite fear of selfish, 'Hobbesian' reactions on the part of ordinary people. A striking example is New Orleans after Katrina, when black people desperate for help were painted as selfish villains, when baseless stories of savagery among the 'natives' fuelled a violent and repressive response by government, police and army, as well as by 'vigilantes'.

Moreover, one needs to be wary even of well-intentioned accounts that dwell on such elite Hobbesianism, and disempower ordinary people in the process. Such an account is Naomi Klein's in The shock doctrine. Klein is absolutely right to point to the tendency of ruthless elite/rich elements in society to seek to exploit disasters and to reconstruct afterward in a way that points in a very different direction to the democratic, quasi-revolutionary spirit unleashed by the people's collective self-help response to the Mexico City earthquake. This elite panic, I would say, is partly about stopping the upsurge of citizenship, fervour and hope that can arise in disaster. But where Klein goes wrong is in suggesting sometimes that this elite activity succeeds in disempowering the victims of disaster, stripping them of their agency. Here is Solnit on this:

"[Klein's book] is a trenchant investigation of how economic policies benefitting elites are thrust upon people in times of crisis. But it describes those people in all the old unexamined terms and sees the aftermath of disaster as an opportunity for conquest from above rather than a contest of power whose outcome is sometimes populist or even revolutionary... It's a surprisingly disempowering portrait from the Left and one that echoes the [unfounded, as the Blitz proved] fears of prewar British authorities, the apparent product of assumptions rather than research...".

She goes on to cite how Fritz himself shows a different path:

"Fritz's first radical premise is that everyday life is already a disaster of sorts, one from which actual disaster liberates us. He points out that people suffer and die daily, though in ordinary times, they do so privately, separately. And he writes, "The traditional contrast between 'normal' and 'disaster' almost always ignores or minimises these 
recurrent stresses of everyday life and their personal and social effects. It also ignores a historically consistent and continually growing body of political and social analyses that points to the failure of modern societies to fulfil an individual's basic human needs for community identity."” (p.107)

We should add to that last sentence, I believe, something implicit in my epigraph from Benjamin: that much of ordinary life under the rule of atomisatory neoliberalism is a kind of constant low-level disaster. Life as low-grade loneliness, despair. Thus, extraordinarily, disasters are felt as a release. What the love, frankly, that people have for disasters that they had to 'endure' shows us - including the actual love that was engendered in them and practiced by them - is the paucity of the 'normal' condition, in the contemporary world. How dehumanised 'normal' human life is. How our isolated, meaning-weak condition is thrown into stark relief by a situation that, though horrific, is nevertheless preferable to that condition. Because at last, for the first time perhaps, we experience real community.

What emerges in disaster is that real community, the very opposite of what the Hobbesian script told us would emerge.

The Hobbesian script is, we should note here, among other things quite literally that, a script. An alarming number of books and films and TV shows suppose that disaster necessarily unleashes the worst in human beings. Consider this, again from Solnit:

"One of the more amusing recent manifestations of Hobbes came as entertainment, starting with the 2000 American television series Survivor... The show seemed to reference Lord of the flies and other epics of savage regression and primordial competition, but merely dropping a bunch of people in a remote location and asking them to cope might have produced uneventful co-operation or unpredictable improvisation. Instead, the show's creators and directors divided the cast into teams. The teams competed with each other for rewards. Eliminating fellow members was one of the competitive games they were obliged to play to increase insecurity and drama within teams. The goal was to produce a single winner rather than a surviving society, a competitive pyramid rather than a party of cooperation. Toiling for food and shelter was overshadowed by the scramble to win out in a wholly gratuitous competition based on arbitrary rules. Capitalism is based on the idea that there is not enough to go around, and the rules for Survivor built scarcity and competition and winners and losers into the system. These people were not in the wilderness but living under an arbitrary autocratic regime that might as well have been Los Angeles or London. The producers pretended we were seeing raw human nature in crisis conditions but stacked the deck carefully to produce Hobbesian behaviour - or rather marketplace behaviour, which amounts to the same thing here." (p.93)

There are many-too-many run-of-the-mill disaster movies etc that have basically the same format as this. Though, interestingly, there are also many that at least posit some kind of heroic team-building as a means to community among the chaos. And then there 
are the stand-out cases, real art, where the whole faux-Hobbesian architecture gets aufgehoben.

I mentioned earlier The Road and The Hunger Games trilogy. These are, actually, clear cases of the latter.

The Road is, on the surface, a remarkably, extremely bleak book/film, a vision of a post-apocalyptic world indeed peopled by Hobbesian monsters. The scenario in The Road is so grim, because the author has manipulated the conditions in his fiction a little like those in charge of Survivor manipulated the 'reality' of the contestants: in the scenario of The Road, some kind of ecological catastrophe has occurred so extreme that it appears that the entire biosphere is dead, except for humans. Thus leading to the remaining few denizens of the world devouring each other, often literally. And yet, what is often missed is the stunningly moving, redemptive ending of the story, as the dying protagonist refuses to give up on the life of his son, refuses to take him out of the world with him, refuses to give up on the future; and as the son is found, after his father's death, by a family who want to take him in, and whose dog - the blessing, added to human fellowship, of a non-human other, loved even more in the absence of other life-forms for us to love - evidently persuades him to say yes.

The Hunger Games may well have put many off from watching/reading it by, once again, the extreme - in this case explicitly manipulative - horror of its premise. A climate-devastated, much-depleted future America is held together by a rabidly authoritarian regime of the $1 \%$, lording it over the destitute rest in particular by means of subjecting them to ritual combat (as a 'reality TV' show) annually. The combat taking the form of randomly selected teen children from each of the poor districts having to seek to survive hunger and cold and fight it out to the death to the last survivor in an arena rigidly controlled for mass-audience-entertainment by their rulers. And yet, the actual story of the Hunger Games is of an emergent struggle against this utterly vicious system; a system that pretends to reveal, as Hobbes claimed to reveal, that only centrally administered violence and inequality can restrain the lower classes from tearing each other apart. (If one disliked they idea of (and perhaps avoided watching) The Hunger Games because one assumed that it was essentially a reality-show-style spectacle of mutual savagery, then there is a risk that one is in fact buying into the highly-dubious elite assumption of what ordinary folk are 'really' like...) In the first part of the trilogy, that struggle begins, with the refusal of the two last survivors to kill each other, an extraordinary act of defiance. In the second part, that act of defiance, that spark, catches fire and in the end launches an outright rebellion, when many of the participants in the new hunger games, participants chosen by virtue of having been survivors of all the previous hunger games, tacitly refuse to kill one another and in particular strive to keep alive the girl who had initiated that defiant first act of refusal. The third part is the story of that rebellion as, with immense selfsacrifice, the districts rise up and finally overwhelm their oppressors. This story explores in gripping and moving detail how human beings can be transformed for the better 'even' by an imposed disaster. I would hypothesise that it is one of the most successful box-office films of all time because of this. 
Given the possibility especially of elite responses to or uses of disaster that amount to a 'second arrow', a new disaster imposed upon the first occurrence of a disaster, the good news offered in section [1] offers no guarantees. We need to sow the seeds for a healthy response to disaster. How then do we do this?

My first suggestion is a simple one: we need to interpret and celebrate stories like The Hunger Games.

And, more important still (for fact is harder to dismiss than fiction): we need to learn and disseminate the learning that Fritz et al achieved, ${ }^{7}$ overcoming deep-set Hobbesian prejudices about ourselves in the process. The remarkable stories of 1906, of 1940-45, of 1985 , of 2001 etc. need to be told and re-told until we have started collectively to twig that we humans are not 'undernearth it all' as rubbish as we are have been told we are. (The ideological claim that 'human nature' is Hobbesian is a false but dangerously self-fulfilling one.)

My next suggestion is that we heed the recommendations offered by Fritz. Consider in particular this remarkable culminatory portion of his text (pp.79-80; emphases mine):

"The situational therapeutic features of disaster and the natural spontaneous techniques of group therapy developed in the community of sufferers might be translated into the following therapeutic action directives [for society/politics]:

1. Utilize the device of shock for disrupting dysfunctional habit patterns and for demonstrating their inapplicability to present needs.

2. Objectify the nature of the crisis and the threat which it poses to the integrity of the personal and social system. Convert anxiety into fear.

3. Clearly specify the remedial needs as ones that require social, as well as individual, adaptation and physical manipulation of the external environment, as well as symbolic manipulation of the intrapsychic processes.

4. Slough off dysfunctional pre-existing interactional norms and values and permit norms and values to emerge in response to present situational imperatives.

5. Establish transcendent goals, which continually challenge individual effort and provide people with a sense of mission in life. Provide people with work roles that clearly and meaningfully relate to societal goals.

6. Democratize social relationships by eliminating invidious social distinctions and material blocks to social mobility and achievement.

\footnotetext{
${ }^{7}$ Not entirely incidentally, a side-benefit of Fritz's work becoming widely read by those whose job it is to prepare for disasters, such as the military, would be that they would be less likely to engage in thoughtless aerial bombardment. For Fritz's work explains more clearly than I have ever seen it explained before why aerial bombardment alone, even when enormously devastating, usually fails to cow a population. For it is experienced as a disaster imposed deliberately upon the community - and the community pulls together remarkably against it. As Fritz documents at pp.51-2 of his text, this phenomenon probably also goes a long way to helping explain the (phenomenal) success story, which has left many scratching their heads, of the Japanese and German economies after 1945.
} 
7. Change the reward structure of the group so that social recognition and reward are based on crisis-induced need and the achievement of social goals, rather than on preexistent ascriptive status.

8. Eliminate formalized role relationships, free the channels for intimate communication, and provide positive social sanctions for spontaneous, direct, informal, sentimental communication and the emotional sharing of experiences.

9 Utilize a few extreme sufferers as a social reference point for enabling others to assess their pain and privation within a relative context.

10. Dramatize the crisis or stress as an event, utilize it as a socially recognized juncture in life experience, and provide social absolution for guilt-ridden actions that preceded the event."

I think if we systematically worked through that list, and applied it in relation to actual climate-induced disasters, and were in readiness to apply it to the 'next generation' of worsening climate-disasters, we would be in good shape. (Think for instance of how we could make a societal habit of numbers $9 \& 10$, here. Think, ultimately, how a healthy 'survivors' ethos' ${ }^{8}$ might be developed around moving beyond the narrative of blame for those (all of us, to a greater or lesser extent) whose actions have precipitated the crisis). The climate-crisis is going to provide us, for better and for worse, with a whole series of opportunities to work through 1-10 on Fritz's list. Let's help make it be for better: by being ready, and even hopeful. ${ }^{9}$

And my next suggestion is that we think deeply about how deeply things need to be overturned - including, about how only something like disaster will, it would seem, do the trick - if we are to turn our current path into something that will not nevertheless yield simply an ever-escalating sequence of disasters until there is no-one left to tell any stories. In other words, what assumptions and paradigms do we need to lose and gain, if we are to be able not only to enter but to thrive in the paradises Solnit has suggested are potentially open to us? How do we make the most of disaster and even breakdown, ensuring that this does not become simply complete collapse?

As Foster argues in The sustainability mirage, 'sustainable development' and moreor-less Rawlsian liberal conceptions of contract/justice/fairness do not produce a solid enough basis to resist temptations towards denial and short-termism (temptations that will only underscore the momentum toward outright collapse), under such pressure. They are part of the paradigm which needs overcoming. Preparing our societies for the onslaught they are very very likely to face requires instead the development of some true

\footnotetext{
${ }^{8}$ My idea here is developed by loose analogy with what Mahmood Mamdani recommends as the kind of ethos ultimately needed in post-genocide situations, as opposed to an ethos of retributive justice.

${ }_{9}$ Solnit herself speaks about what this hopeful readiness and community/citizen responsiveness actually means in powerful ways in this interview: http://www.truth-out.org/op-ed/item/14193rebecca-solnit-on-how-disasters-can-move-us-from-a-sense-of-self-interest-to-a-sense-ofcommunity . Cf. also Saci Lloyd's immensely hopeful brace of stories about collective response to incipient climate-chaos, The carbon diaries.
} 
selflessness and of the healthy enlightened selfishness of taking care of oneself, one's family, one's 'village', one's neighbours. Of charity beginning at home.

In the next section, I suggest one way in which intellectuals might contribute to that process of preparation. Namely, by highlighting a happy, under-understood connection between our care for our children and a more general care for posterity, for what comes after us. A way in which we actually can generate a bridge between warm local care and even (enlightened) selfishness, on the one hand, and 'sacrifice' for the sake of the deep future, on the other.

[3] I would argue that, in the great peril that our species faces, one thing we must do is: seek to relocalise our world. ${ }^{10}$ To improve resilience; to achieve democracy where it can actually be achieved, in communities; and to ensure that there are at least 'islands' that survive the grave peril. We ought to take advantage of the growth of community-spirit that, if we are prepared in the right way, we can grow from the pressure that we get put under by a rising tide of climate-disasters. Community-spirit normally begins locally (the word "community" is, obviously, a clue here...).

So then, what if — in looking for tools with which to re-imagine our world such that we are better prepared to find and grow this new (spirit of) community - we started as locally as possible? What if we started with our own families?

For, once more, I think that one thing that Foster has helpfully shown, in his books critiquing 'sustainability', is how implausible it is to think that nostrums such as 'global justice' and 'sustainable development' are going adequately to motivate the kinds of actions/thinking now needed. We need to start, quite literally, closer to home; we need to start with something adequately motivating. The claim that a survivor of disaster makes on us when they present themselves to us is a model here. Their vulnerability is what first moves us. ${ }^{11}$

Following Foster, I am sceptical of the claim that new 'global values' such as are embodied in the global justice paradigm, or in the Millennium Development Goals (or their contemporary heirs, the Sustainable Development Goals) would be adequate - and I am sceptical that they are needed. I think that what we ought to be doing is helping everyone to see that the values that they already have are enough, if only those values get thought through properly, and acted upon. This will be the remarkable, hopeful claim of this section.

What do people value? Well, isn't the one thing we still value above all others our children - even in our debased liberal society that, as well as delivering some real emancipation, has damaged the

\footnotetext{
${ }^{10}$ Here, my thought is in concert with that of Helena Norberg-Hodge; see for instance her groundbreaking work, Ancient futures.

${ }_{11}$ Here, I am drawing on the argument of Christopher Groves's book, Care, uncertainty and intergenerational ethics.
} 
meaning of family, by raising commercial bonds to a far greater importance? Starting with their utter vulnerability, their profound dependence. Doesn't everyone, from the most idealistic to the most cynical, concur in profoundly valuing at the very least their own children?

What is it to value one's own children?

You might think that valuing only one's own children won't take things very far. That it would result in a selfish, short-termist, present-centric way of being. But: If you truly value your own children, two important points follow that completely contradict such pessimism. Once they are understood, if they become widely-enough understood, then the change of priorities needed in order to head off the vast threat that at present humankind poses to its own posterity (e.g. via our messing with the climate) might conceivably start at last to come about:

i) If you value your children not just for your sake but for their own, it immediately follows that you must value what they most value. If you were to stomp on everything your children held most dear, you would be denying them their independence, their selves, their lives. What can we expect our own children to value above all other things? A reasonable expectation is that they will be broadly similar to us; for after all, they are not only animals, but mammals; not only mammals, but primates; not only primates, but human; and not only that, but - our very own children. In other words: the one thing they are likely to value above all others is: their own children... It can quickly be seen that this point repeats endlessly. In other words: Merely valuing profoundly one's own children ramifies into valuing just as profoundly all one's descendants. If you truly care about your kids, then you care about their kids: and so on, ad infinitum. (It is important to be clear that the degree of care mustn't ebb a little with each generation: if you really care most of all for your kids, then, as I've said, you will care just as profoundly for what they care for -- their kids -- and so on, indefinitely into the future. If you weren't to care as much for your grandchildren as you do about your children, then that would just be a roundabout way of saying that you didn't care as much as you claimed to do about your children. So: your care for your children directly motivates care for theirs, and so on, wonderfully, endlessly...)

ii) Who will one's descendants be? How can one determine who exactly to care for so profoundly? A reasonable expectation is that, just as one has more and more ancestors as one goes back in time (twice as many grandparents as parents, and so on), so one will probably have more and more descendants as one goes forward in time. With each successive generation, then, one's descendants become more and more widespread. Over time, they are likely to be spread wider and wider across the world. If you truly care about your kids, then, we have established (See (i), above) that you care about all your descendants just as much. Now we see that those descendants are legion, more numerous and almost certainly more geographically widespread with every generation. (Given that you cannot anticipate exactly 
where your descendants will end up, the only sensible, precautious course is to assume that there will be no geographical limits to their spread, given enough passage of time.) You can't take care of that worldwide legion across aeons by (e.g.) making them all rich, or building them a fort. The only way you can do it is by preventing them from being subject to catastrophic threats. Of which, in the present article, we have been dwelling as an exemplar on one in particular, the one pressing hardest on us: that of climate-catastrophe and its baggage of climate-induced-'natural'-disasters.

We humans are not used to thinking this way because none of us can anticipate the precise details of our future family-tree. But such precise knowledge is unnecessary: (i) and (ii), above, together add up to an incredibly powerful 'reminder' of what it is that our children really are to us.

What is the best way we can take care of what we most value? (And: What we most value, we can now see, is not only our own kids narrowly-conceived, but the ongoing unfolding of the generations that will follow them.)

One doesn't need to be a tree-hugger or a wildlife-lover (or anything else that you, dear Global Discourse reader, probably are, but that you might despair that most of the populace are not), in order to become clear that we simply have to take care, together, of the future of our home. Our fragile Earth. For, without this home, what we most value is nothing.

One doesn't even need to care about 'future generations' in the abstract. All one needs to do is to care about one's very own children, for themselves (as opposed to: as playthings, for you). That is enough to unleash a care that encompasses the entire human future time-wise, and the entire globe space-wise. If you truly care about your own kids, as surely you do, as pretty much everybody does, then, whether or not you have realised it before, you care about all your descendants just as much, and they will encompass all the future and (eventually) all the globe.

What are the practical implications of this? I'm asking you and all of us to think about -- to imagine, to envision, and to feel in your heart -- the effects of our policy-decisions (e.g. in relation to climate) on our children, and on their children, and on their children, and...

Take an example: fracking. If you care about your kids, as you surely do, you might think that, if you're only thinking of them, fracking will at least benefit them (and you) by providing them (and you) with power. But once you are thinking just as much, as you must if you are truly to care for your children, about your grandchildren, your greatgrandchildren, and your many scattered greatgreatgreatgreatgreatgreatgreatgreatgreatgreatgreatgreatgreatgreat...grandchildren, then fracking - with its long-term shattered landscapes, its methane leakage, its hefty contribution to 
climate-damage, its locking in on patterns of dependence on fossil fuels, its corporate capture starts to look a rather less attractive option.

Take another example: Christmas. If you care only, narrowly, about your kids, you are perhaps already buying them big presents for next December 25th. After all, who wants to be a 'Scrooge'?! But, once you get clear that what it is to really care about your kids is to care about their descendants, ad infinitum, then the matter becomes different; and, in a way, simple. It is just wrong to give kids presents that come at the cost of the future... It is doing wrong to them, to do this. (Sure, when they are very young, they may struggle to understand this. But when they are just slightly older, you can explain it to them, and they'll be grateful, or at least intrigued. And one thing that follows from this article is: You must explain it to them. And even: to everyone. This idea, that true care for one's own kids must translate into care not just for the 7th but for the $\underline{777}$ th generation, needs the widest possible dissemination...)

Before finishing this section, let me consider one important possible objection. Does my argument presume that people who are engaged in environmentally-destructive activities (e.g. CEOs of oil companies) don't really care about (their own) kids? The answer is: No. What I have done in this section, rather, is to seek to set out how caring for one's kids, once one understands what really caring for one's kids entails, already motivates any and all of us NO LONGER to engage in environmentally-destructive behaviour. Because, once the CEO of Shell truly realises that to care for his own children means caring for future generations across the world, then he will instantaneously be motivated to at least look again at his practices. (So, if you get a chance, please show him this article, or at least relate to him the point of this section of it... That would be a really great way to show that you care for your kids...)

The argument that l've made in the present section should provide some hope. If we can only spread some deep awareness of these fundamental points that I have made here, then humankind might start to act with more serious long-term vision. This vision begins from and in a way ends with the the care that we preternaturally have for our own children. Once we as parents realise that we cannot mean it when we say we love our own kids unless we think and act in a truly long-term and global fashion -- and once this 'meme' starts itself to spread around the globe -- then hope might at last start to undo threat. For, remarkably, it will be enough to save this world as a place for human beings to flourish far far into the future, if only we take seriously enough that we love our own kids.

What our values require of us is at minimum: decisive action, with determination, to do everything we can for our children, and all that this means. In order to serve our children adequately, we must do right by their children. Once we get enough folk to understand what I've argued here, the tide may at last start to turn in our favour. And what that means, given what our values are, is: in favour of our children, in favour of all our numberless descendants, and in favour of what they need in order to flourish: flourishing, restored ecosystems... 
Don't do this just because it's 'green', nor even because it's 'rational'. Do it for the children. Do it from your heart. Take this idea seriously. For, way beyond the readership of this fine journal, it's an idea that can catch fire...

And it has the profound advantages over currently-dominant 'sustainable-development'style thinking of (I) promising to motivate changes that will be enough, rather than superficial band-aids, and simultaneously of (II) not requiring excessive or over-ambitious generosity or values-shifts. For it begins, literally, at home. It begins in care and in response to vulnerability (and there is nothing or no-one more vulnerable to us and our power than our descendants). It begins in the same kind of 'place' that gets extended in the cases that Solnit et al tell us of. Disasters yield community. The most elemental community of all, our own family/children, bids us, once we have thought matters through, do much much more than we are doing to provide a basis for an ongoing human community that will not be shattered.

For we have never been isolated egos, even if that is what ad-men and too many philosophers alike tell us that we are.

And what the argument of this section does is to show how a care that begins at home cannot remain at home. The kind of immediate pull upon us that occurs with our own families, and that occurs in disaster, needs drawing out way across time and space, if it is to be realised. You cannot succeed any more in caring for your kids by keeping your horizons narrow.

Foster, in his splendid, incendiary most recent book, After sustainability, emphasises rightly that our concern for a better future needs to take place now, and needs to involve a rigorous and honest being in the moment. Typically, we are anxious about and ineffective at being honest / being in the moment, in part because we know deep down that we are sowing the seeds of the future's destruction.

Such being in the moment is actually one of the key things made possible by, unconcealed by, disaster. Disaster enables us to be present.

And this is a very good thing, a gift in time. For, just as Foster would suggest, the implications of taking the pulse of the future for how we feel, live and act today are of course critical. All our thinking about the impact of future disasters and, more generally, about the well-being (or otherwise) of future generations is in part, crucially, a way to think about how to do the right thing NOW. And what the ways of thinking about the future outlined in the present piece underline is what is in any case obvious: that today's (individual and especially collective) action WILL make a huge difference in the future. Changes now will not only make us be better prepared to deal with the coming disasters (including both the damage and the potential silver-lining), but are also likely to help preempt disasters and reduce their scale. In other words, whether it is movies, scientific studies or philosophical articles, it is the thinking about future disasters which should wake us up RIGHT NOW. ${ }^{12}$

\footnotetext{
${ }^{12}$ Many thanks to Peter Kramer, for formulations of his that I have borrowed to emphasise this point of mine. I return to emphasise this fundamental point at the close of my conclusion, below.
} 
But: I think it is clearly implicit in what I have said that we also - as well as a greater focus on the present, that Foster rightly urges - quite desperately need a greater focus on the deeper future. (Foster fails to distinguish between the near-future - 5/10 years - and the deeper future - 50, 500, even 50000 years. That latter is what is ignored in our culture of chronic short-termism.) Properly understood, this emphasis on the deep future, on life splendidly going on in(de)finitely long beyond our horizons, goes hand in hand with a focus on ourselves now. We spend all our time running away from the present into the near-future (and into regret at the near-past etc.). We distract ourselves, whether with plans for a new kitchen or for a new 'development'-project. But such running away into the near-future is at the same time a running away FROM the deep future. For the sake of jam tomorrow, we are depriving our great-great-great..-grandchildren of life and love. In growing the pie, we are planting a depth-charge under the ecosystems of the deeper future.

The argument of the present section has shown, at least from an engaged thoughtful and feelingful standpoint, the direction of a route to dissolving the depth-charge. The focus on the deeper future, that we so badly need, can come, via the simple, powerful route of focussing our attention on our children, ${ }^{13}$ and seeing them in their true sense: as themselves (not appendages of us), and as harbouring a permanent future.

Have I claimed here in section 3, in a display of absurd idealism, that it would be enough, just to get everyone to think seriously about the argument l've made in this section? Yes and no! NO, in that I have been quite clear that there are many things that actually need to change, to be done, and some of these changes will be a titanic struggle (one that we are likely, usually, to lose). And of course l've stressed upfront that there are disasters coming that we are already 'committed' to; that we cannot head off. But also Yes: in that if somehow one were able to get enough people to think through the argument of this section, that would be truly transformative; and yes, in that this is at least something that (suitably feeling-ful) intellectuals/philosophers, can offer right now, that speaks to our condition; and yes finally, in that I believe, as I will conclude by suggesting more explicitly, that the coming climate-induced-disasters may well concentrate the mind such that we have more chance of reaching a tipping point vis-a-vis our care for our children and for each other than might, right now, seem likely to you.

[4] To conclude. William James famously suggested that we stand in need of a moral equivalent of war. To give us meaning and bind us together, in times of (seeming) nondisaster, in times of peace. Without there being such a moral equivalent of war, James thought — rightly, in my view — that we would splinter into mutually-indifferent pleasure-

\footnotetext{
${ }^{13} \mathrm{My}$ idea here is close to that of Naomi Klein, in her This changes everything (see especially the closing chapters of that book). She sees the 'climate war' we are now starting to fight partly through the lens of her new motherhood. Anthropogenic climate change is hitting and will hit our kids hardest (of those who are alive today). And their kids, almost certainly, harder still... If we really attend to our children, we have no option but to fight it.
} 
centres. That scenario has, I fear, been realised much more than is prudent, in the modern North, under the rule o the political philosophy of liberalism. But it is on the point of being unrealised again.

And that may, for all its horrors, bring us a gift we badly need.

My hypothesis is that the moral equivalent of war is about to be forced upon us.

I have argued (1) that the sadly-likely litany of worsening climate-chaos-part-caused unnatural disasters that we will experience need not, as many fear (and as I too feared, til recently), simply sap our morale and resources, debase our culture, and hasten a descent into a Hobbesian condition. Into collapse. What Rebecca Solnit et al have helped to show is that the Hobbesian assumption that people under severe strain become 'animals' is highly dubious. It is itself a piece of ideology that tends to be used to legitimate authoritarian, destructive behaviour by elites, behaviour that comes from fear (or sometimes venality) that is illicitly projected onto ordinary people.

What we need to do, therefore (2), is to seek to prepare for these disasters, in a positive spirit. The word needs to be spread. People need to understand that they can expect others, and themselves, to be resolute, in the face of disaster. Disasterpreparedness plans should not emphasise repression and authoritarian control; they should emphasise empowering ordinary people to be amazing. As Disaster Studies appears to show people usually spontaneously are, unless elite-panic gets in the way.

We need to build for the resilience of immediate local practical action - and simultaneously grow that into a new collectivistic ethic of long-term global care (3). We need more than cool justice; something more immediate (though, remarkably, such care iterates, as I showed in (3)). We need to foster the kind of care that is unleashed in disaster. In the disasters that are coming.

At the opening of section [1], above, I spoke of the likelihood that our rupturing of the limits to growth (of which dangerous climate change is only the most developed example) may lead to an irrecoverable civilisation collapse, within the next generation or two. The remainder of this paper since then can naturally be read as an attempt to think through how yet to avert such an outcome.

But there is another way of reading it, too, both more pessimistic and more optimistic than that. For, if Fritz and Solnit are right — and I am confident that they are then perhaps our worry about 'irrecoverable civilisational collapse' can be downgraded much further. Perhaps what we should assume instead is that, even if our rupturing of the limits to growth continues and humankind proceeds on the trajectory of collapse through rapidly rising mortality etc. that we find in most of the Club of Rome scenarios, still human beings will rally, and will keep on and on turning the hells that we've created by so recklessly tampering with the conditions of our collective life-support system (the living planet) into mini-heavens.

And that is an encouraging thought.

The worry remains, even here, that the field of 'Disaster Studies' has focussed mostly on isolated disasters. The era of dangerous human-triggered climate change promises to 
some extent a new problem: a ratcheting up of connected, ramifying disasters (unless we manage to turn the supertanker of civilisation around, and start to reduce our exposure to the whirlwind, and (after a time-lag) to reduce the whirlwind itself, rather than evermore reaping it). Will we be able to maintain the kind of admirable spirit and humanity that Disaster Studies seemingly shows us, under such long-term pressure?

Here is one reason for thinking that we will. I have suggested that what our atomised, individualised society desperately needs is: means and occasions to rebuild community. ${ }^{14}$ The horror, death and squalor of climate-caused disasters will not be unmitigated, not by any means. I have suggested that it will likely, as a 'silver-lining' to those unprecedented storm clouds, facilitate just such a rebuilding of community. Now; what if we were able to parlay that into something bigger? What if the spirit of community starts to reach more globally, and even across time? In section 3, I suggested a concrete way in which one can start to imagine that happening. For I showed that one role that a philosophically-informed deep-reframing can play in the needful process of virtuous preparation for (and prevention of) disasters is in helping people to understand that, in order to care for their children, they need to care for their children in turn, and so on, ad infinitum. Philosophical thinking, global discourse, inter-temporal discourse could start, in other words, to multiply the renewed sense of community that I postulated and recounted in section 1. We are willing, at times of crisis and disaster, to act in ways that astonish us and make us proud to be alive. Won't we show that same compassion to our own children? What doing so means, as l've laid out, is: planning now — starting now — to build down the terrible threat which we are currently hanging over them and theirs. As Homer-Dixon's work, drawing on the respected scholarly work of Joe Painter and Buzz Holling, ${ }^{15}$ suggests, and as my work alongside Nassim Taleb on the Precautionary Principle also strongly suggests, we'll surely simplify and scale down our societies, and reduce our impact on the natural world, at some point. The issue is whether the next run of climate-disasters prompts this pro-active catagenesis, or whether we have to wait for fullscale collapse to force it upon us...

Thus we can see clearly at last the outlines of the greatest gift that climate disasters can bring in their wake, if we are ready to accept it. A gift that would stop us having to look for silver linings as we descend into collapse, and genuinely be able rather to head off that collapse... An unleashing of humanity, of decency, of care. That we can scale up.

Because: these disasters show the future on a business-as-usual scenario. They show it in its horror. But they also show us the riposte. Holderlin's great dictum holds true: Where the danger grows, so does the saving power.

\footnotetext{
${ }^{14}$ Has our society already become too atomised even to be capable of a 'paradisical' response to disaster? I have already given my answer to this question: No. Let me put the point slightly humourously: if 21 st century New Yorkers can manage it, then anyone can...

${ }^{15}$ See especially pp.226-233 of Homer-Dixon, for his take on Painter and (especially) on Holling's 'panarchy' concept, giving us a clear upside of down: the chance to refresh and simplify our systems - much as ecosystems do, when they break down.
} 
For, if I am right in thinking that climate-disasters can bring a massively enhanced community-consciousness in their wake, that means that they do after all have the capacity that many of us have been hoping that they might: to wake us up. Thus, and here I think I differ from Foster, we really can still dare to hope that we may collectively wake up enough before we have committed our civilisation to breakdown, let alone to collapse. ${ }^{16}$

${ }^{16}$ Thanks to Peter Kramer and lan Christie for invaluable comments on earlier drafts. Thanks to Sam Earle for the concept of the 'imaginary', a concept that she is developing in her PhD thesis with me. 
Reference List:

Cormac McCarthy (2006). The Road. Random House: New York.

Foster, John (2008). The Sustainability Mirage: Illusion and Reality in the Coming War on Climate Change. Taylor \& Francis Ltd: London.

Foster, John (2015). After Sustainability: Denial, Hope, Retrieval. Routledge: Oxon.

Fritz, Charles (1996). "Disasters and mental health: Therapeutic principles drawn from Disaster Studies". [Unpublished]. Available at University of Delaware library:

http://udspace.udel.edu/handle/19716/1325

Groves, Christopher (2014). Care, Uncertainty and Intergenerational Ethics. Palgrave Macmillan: Basingstoke.

Homer-Dixon, Thomas (2006). The upside of down: Catastrophe, creativity, and the renewal of civilisation. Island Press: Washington.

Klein, Naomi (2007). The Shock Doctrine. Penguin Books: London.

Klein, Naomi (2015). This Changes Everything. Penguin Books: London.

Lloyd, Saci (2009). The Carbon Diaries 2015. Hodder Children's Books.

Norberg-Hodge, Helena (2009). Ancient Futures: Lessons from Ladakh for a Globalizing World. Sierra Club Books: San Francisco.

Solnit, Rebecca (2009). A Paradise Built in Hell: The Extraordinary Communities That Arise in Disaster. Penguin Books: London

Taleb, Nassim et al (2015). The Precautionary Principle (with Application to the Genetic Modification of Organisms). NYU School of Engineering Working Paper Series. Available at: http://www.fooledbyrandomness.com/pp2.pdf 